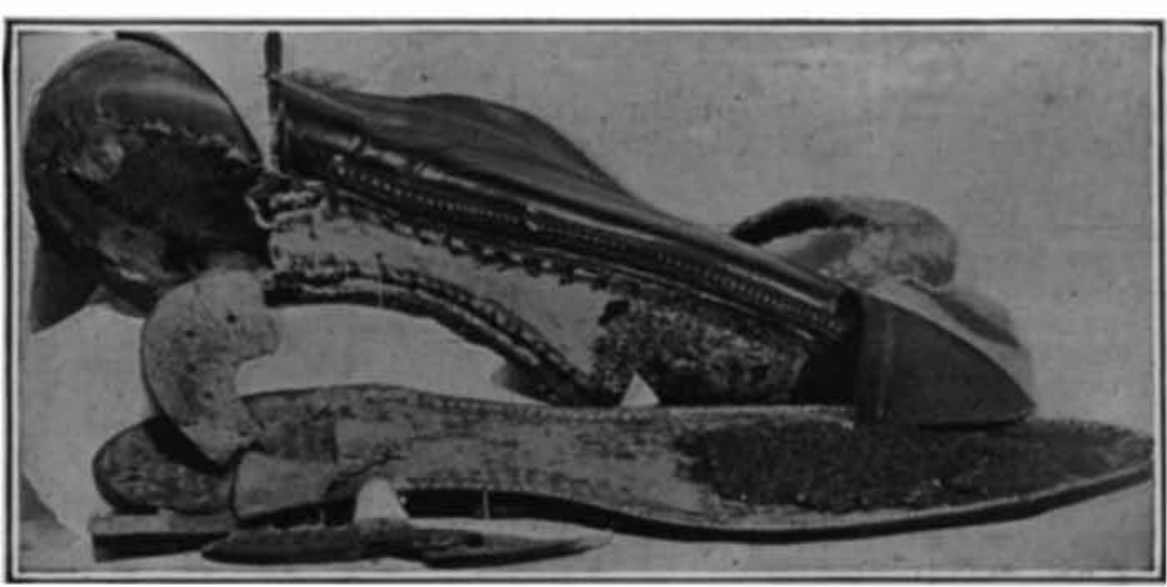

The part-paper shoe torn apart reveals a very thin innersole with canvas back, fiber box toe and counter, paper in undersole and half-paper heel

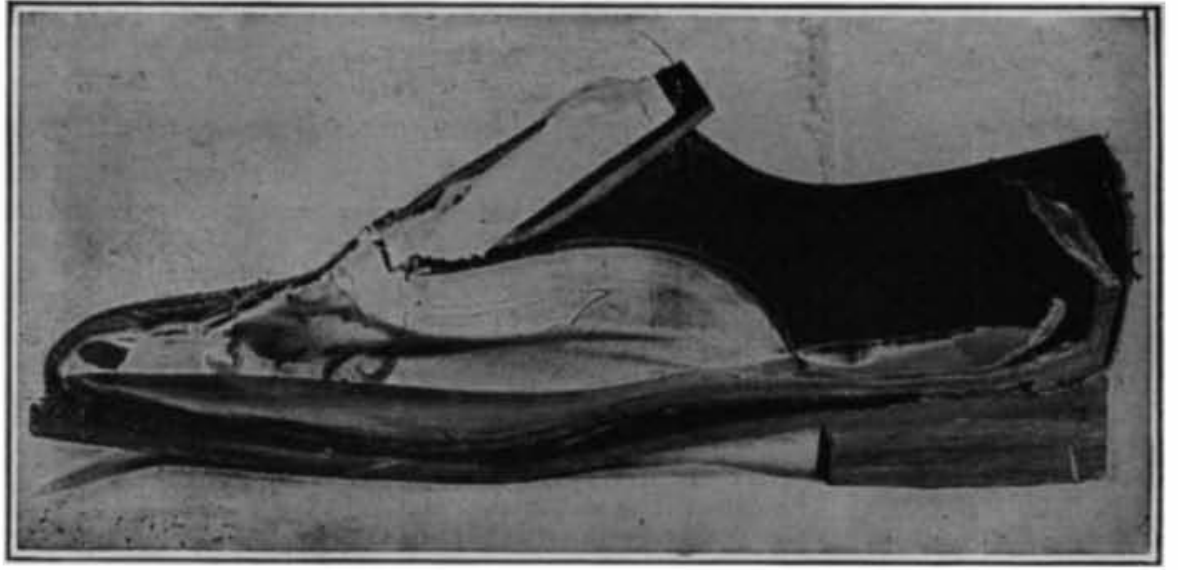

All leather shoe split in half. Note heavy leather for innersole. Steel spring supports the instep; cork filling between inner and outer soles

\section{How Much Paper in Your Shoes?}

By Ralph Howard

T'S rather hard to believe that half of us are wear1 ing shoes made of part paper, but such is the fact Authorities agree that fully half of the shoes being manufactured contain a percentage of paper.

This is not only true of the cheap shoes but of socalled "high-grade" lines, selling from $\$ 10$ a pair up wards. The use of paper reduces th wearing qualities of the shoes, but it is probable that all-leather shoes made at the same cost would not wear as well. The saving effected by using paper permits the use of better leather in the parts most exposed to wear.

Pressed paper is often used for the upper layers of the heel, and shellacke fiber is used for box toes and "counters." Another method of saving is to split the leather inner sole into two, and line them with heavy canvas. Thus two inner soles are made from the leather ordinarily used for one, at only a slight increase in price over one piece.

A shoe so constructed is likely not to "hold its shape" well, especially in wet weather, although, if a good quality of leather is used in the sole and uppers, it may give good wear. Makers of allleather shoes maintain, however, that it is good economy to pay a couple of dollars more for shoes in which no paper is used.

The substitution of paper for leather is so well done, however, that it is impossible to tell from ordinary observation whether paper is used in the shoe or not Even experienced shoe buyers find it difficult to tell and usually rely on the statement of the manufacurer.

One shoe buyer for a chain of large stores has originated the practise of tearing up one shoe of each case lot he buys to see just what material is used. If he finds any paper in the sample selected at random, the whole shipment is returned. These stores pride whole shipment is returned. These stores pride themse.

A simple test is usually effective in determining whether or not a shoe is all leather. If paper is used, it is usually in the upper sections of the heel. If the point of a pocket knife is pressed on this part of the shoe, with the width of the blade parallel with the layers, it will readily sink in if the heel is of paper, but leather will resist quite heavy pressure from the knife.

If paper is found here, it is good evidence that it has been used elsewhere in the shoe. Another test is to bend the counter inward. If it is of leather, it will at once spring back into shape, but if paper or fiber is used the counter will remain bent. A similar test can be applied to the toe of the shoe. If the box is pressed in, it is so resilient that it will spring back if of leather, but will remain permanently dented if made of paper.

Electric Power from Sunlight By Paul Kirkpatrick

C 1 of the radiant energy of the sun for the purposes of mechanical motion instead of pursuing it around through the indirect and labor-involving processes of organic growth, evaporation, combustion, or other of its secondary terrestrial ef- fects, is both important and fascinating. The problem has always been a leading one in the interests of experimenters and it is clear that a complete solution would have profound effects upon human life.

The instrument shown in the accompanying illustrations is one which develops its small amount of power immediately upon exposure to sunlight. It is a form of electric motor yet is independent of batteries or any external current source, its minute currents being

that at all times three of the six thermo-couples are reached by the rays. These become warm relatively to the three which are shaded. Currents result which, traversing the armature wires, react upon the magnetic field and cause rotation as in any electric motor. As rotation proceeds each couple at a certain point crosses the boundary of shade and changes from hot to cold or vice versa and so the currents preserve their proper directions at all times, the device of the screen serving for the brushes of an ordinary direct current motor.

The motor will operate under the action of sunlight or an electric lamp or any other source of energetic radiation, visible or invisible. If the position of the shading screen is properly altered the the shading screen is properly altered the cle of carbon dioxide snow of the size of a match head placed near the armature on the exposed side will also reverse the rotation. A convex lens of glass may be used to concentrate the radiations instead of the metal cone shown, but being opaque to long waves the glass absorbs much of the useful energy of the inci(lent rays.

\title{
Fighting for Healthy Plants
} By W. A. Murrill

T HE science of plant pathology, or the 1 investigation and control of diseases of plants, particularly those caused by fungi, has been pushed forward of late

Yet one is all leather and the other part paper

thermo-electric, resulting from the heating radiation which falls upon it. The currents arise within the armature and do not leave it.

Of the motor's separate parts, the drum armature, resembling a cage, is made up of vertical wires of silver joined at the upper ends to short spokes of German silver. The junctures, the seat of the electromotive forces, are fiattened to present a greater area to the rays impinging upon them, and are blackened to facilitate quick temperature changes. Models with two \section{four and six armature members have been found successful but those with the larger} found successful but those with the larger
number possess a smoothness of action siminumber possess a smoothness of action simi-
lar to that gained by the use of many cylinlar to that gained by the
ders in a gasoline engine.

In operation the armature is carried by one bearing, a jewel, in the pole gap of the large permanent magnets. An iron core is also placed in this gap, strengthening the magnetic field and providing a support for the jewel. The conical metal refiector may be used to concentrate the radiations, which be used to concentrate the radiations
strike into the pole gap vertically.

A screen is disposed here in such a way with greatest rapidity in the United States.

During the period of the war our experts in this field from the different states coöperated very closely to save as much as possible of every crop from the ravages of disease; and during the summer of 1919 this idea of coöperation was continued and extended with great success. In the neighbohood of New York City, two important field meetings were held, one on Long Island and one at New Haven, Connecticut, for the study of diseases common in those localities.

The first meeting, in June, for the study of potato diseases in particular, was attended by about one hundred plant pathologists representing many parts of America, England and Holland. The farmers furnished motor-cars and tours were arranged for the chief potato-growing sections of Long Island. In the evenings, mosaic, leaf-roll, wart disease, and other potato troubles that have been found difficult to combat were discussed at length, with the best experts in the world on the spot to put their heads together and work out the best methods of control.

The second meeting was held in August and was attenclecl chiefiy by experts from New England and New York. A-utomobile tours covering a distance of three hundred miles were made to plantations, gardens, and nurseries between New Haven, Hartford, and Storrs; while every evening of the week was devoted to papers and discussions. The largest greenhouses in America were seen at Cromwell, where 22 acres are under glass, one house being 800 feet long and another 500 feet square, the latter entirely filled with roses. The largest elm in the United States, at Wethersfield, is $30 \mathrm{ft}$. in circumference, $97 \mathrm{ft}$. high, and 250 years old.

A day was spent in the tobacco-growing regions of Connecticut, where broadleaved tobacco is grown in the open and narrow-leaved varieties are cultivated under tents. At one place were seen 290 acres under cloth.

Left: The motor assembled. Right: The parts congets in stand.

Motor that operates through the electromotive force of hot and cold junctions of a thermocouple, giving minute power when merely exposed to the sun or a lamp 